\title{
Memoria del dolor, deconstrucción y reconstrucción del sujeto*
}

Memory of pain, deconstruction and reconstruction of the subject

Memória da dor, desconstrução e reconstrução do sujeit

Fecha de entrega: 7 de septiembre de 2015

Fecha de evaluación: 14 de septiembre de 2015

Fecha de aprobación: 15 de julio de 2016

Myriam Jiménez Quenguan**

\section{Resumen}

Esta reflexión sobre la memoria del dolor se realiza con base en la particular propuesta narrativa y ficcional de la obra La carroza de Bolívar del escritor Evelio José Rosero Diago, Se pretende deconstruir al sujeto mítico, encarnado en el aparente héroe latinoamericano Simón Bolívar; desde una lectura diferente de la oficial se traen al presente hechos dramáticos ocurridos en el sur de Colombia durante el siglo XIX: la batalla de Bomboná y la llamada Navidad Negra. Así mismo, se visibiliza la reconstrucción del sujeto colectivo, desde la visión irónica

* DOI: http://dx.doi.org/10.15332/s0120-8462.2016.0115.10

* Doctora en Filosofía Tesis Cum Laude por la Universidad Complutense de Madrid; Magister en Literatura Hispanoamericana por el Instituto Caro y Cuervo; Licenciada en Filosofía y Letras, monografía laureada y Grado de Honor por la Universidad de Nariño; Diplomado en Mujer y Género por la Pontificia Universidad Javeriana. Profesora especialista en Lengua y Literatura Española e investigadora en Lengua y Literatura Española por el Ministerio de Asuntos Exteriores, Agencia Española de Cooperación Internacional. Correo electrónico: egraespejo@gmail.com 
de los descendientes de las víctimas, puesta de manifiesto en la Fiesta de Blancos y Negros.

Más allá de la recreación e interpretación histórica, se invita a cuestionar la manipulación de un sujeto que conjuga una serie de intereses y juegos de poder. Para desentrañar lo oculto y para que aflore una nueva conciencia vital, la lectura y la estrategia deconstructivista, ayudan a resaltar la importancia que representa para la salud del pueblo, no solo la visión crítica de su memoria, sino también la desestructuración de la mentira. En la novela la invención de lo carnavalesco es el acontecimiento que permite depurar odios y crear una conciencia reconciliada de la vida; así el autor logra demostrar la grandeza de un pueblo, capaz de sanar heridas físicas y culturales a través del no olvido y la ironía dionisiaca.

Palabras clave: Memoria, deconstrucción, sujeto mítico, sujeto colectivo, Evelio José Rosero, Simón Bolívar, Sañudo.

\section{Abstract}

This reflection on the memory of pain is made based on the particular narrative and fictional proposal of the work La carroza de Bolívar (Bolivar's chariot) by the writer Evelio José Rosero Diago, intends to deconstruct the mythical subject, embodied in the apparent Latin American hero Simon Bolivar; from a reading different from the official ones, dramatic events occurred in southern Colombia during the nineteenth century are brought to the present: the Battle of Bomboná and the so-called Black Christmas. Likewise, the reconstruction of the collective subject is visible, from the ironic vision of thedescendants of the victims, highlighted in the Blacks and White's Carnival.

Beyond the recreation and historical interpretation, it invites to question the manipulation of a subject that combines a series of interests and games of power. In order to unravel the hidden and to bring out a new vital consciousness, reading and deconstructivist strategy help to emphasize the importance that represents for the health of the people, not only the critical vision of their memory, but also the disintegration of the lie. In the novel the invention of the carnival is the event that 
allows to purge hatreds and create a reconciled consciousness of life; thus the author manages to demonstrate the greatness of a people, capable of healing physical and cultural wounds through non-oblivion and Dionysian irony.

Keywords: Memory, deconstruction, mythical subject, collective subject, Evelio José Rosero, Simón Bolívar, Sañudo.

\section{Resumo}

Esta reflexão sobre a memória da dor realiza-se baseada na particular proposta narrativa e ficcional da obra La carroza de Bolívar do escritor Evelio José Rosero Diago. Pretende-se desconstruir ao sujeito mítico, encarnado no aparente herói latino-americano Simón Bolívar; desde uma leitura diferente da oficial se traz ao presente fatos dramáticos acontecidos no sul da Colômbia durante o século XIX: a batalha de Bomboná e o chamado Natal Negro. Também visibiliza a reconstrução do sujeito coletivo, desde a visão irônica dos descendentes das vitimas, que se manifesta na Festa de Brancos e Negros.

Além da recreação e interpretação histórica, convida-se questionar a manipulação de um sujeito que conjuga uma serie de interesses e jogos de poder. Para desentranhar o oculto e para que aflore uma nova consciência vital, a leitura e a estratégia desconstructivista, ajudam a resaltar a importância que representa para o bem-estar do povo, não somente a visão crítica de sua memória, senão também a desestruturação da mentira. No romance a invenção do carnavalesco é o acontecimento que permite depurar ódios e criar uma consciência reconcialada da vida; assim o autor consegue demonstrar a grandeza de um povo capaz de curar feridas físicas e culturais a través de não esquecer e a ironia dionisíaca.

Palavras-chave: Memória, desconstrução, sujeito mítico, sujeito coletivo, Evelio José Rosero, Simón Bolívar, Sañudo. 


\section{Introducción}

Si alguno viene a mí y no odia a su padre, a su madre, a su mujer, a sus hijos, a sus hermanos, a sus hermanas e incluso su propia vida, no puede ser mi discípulo

Lucas. XVI, 26.

El hombre sufre tan terriblemente en el mundo que se ha visto obligado a inventar la risa Friedrich Wilhelm Nietzsche.

El dolor es inevitable, el sufrimiento es opcional. Siddarta Gautama (563 a. C., 453 a. C.).

En la tradición occidental desde los griegos se consideraba importante no solo el cuidado del cuerpo sino también el de la mente y el alma. Sin embargo, la humanidad a lo largo de estos tiempos ha ido olvidando el valor supremo y sagrado de la vida, para convertir en un bien la riqueza material, y desde este antivalor se ha ido olvidando de la memoria; como consecuencia, es dramática la falta de conciencia y la creciente corrupción de la sociedad.

En América Latina y en concreto en Colombia, es preciso que se convierta en imperativo el no olvidar; a veces los silencios otorgan y pueden matar. No se trata de abrir heridas porque sí, sino de conocer y sanar todo aquello que ha producido dolor como la injusticia, la muerte, la guerra, la violencia, el miedo, el terror, la inconsciencia. Es necesario reparar, reflexionar sobre qué bases está construida la historia desde las épocas prehispánicas hasta la conquista y sus diversas manifestaciones posteriores. Es preciso tener en cuenta que en este país, la no aparición de múltiples relatos privilegia solo algunos y excluye a la mayoría; ¿Dónde está la voz del indígena, del negro, de la mujer, del campesino, del pobre? No pocas voces fueron y siguen siendo apagadas, igualmente, muchos crímenes siguen impunes, ¿Por qué?

¿Sobre qué bases está construida la sociedad? ¿Cuáles son las causas de la falta de memoria y el creciente dolor? ¿Qué es lo que se oculta y por qué? ¿Qué es lo que se revela? ¿Es posible seguir guardando silencio frente a la infamia? ¿Es válido justificar el horror? ¿La sociedad occidental sigue repitiendo pruebas como las vividas por Abraham? ¿El padre tiene que sacrificar a su hijo? ¿Es preciso que existan héroes? ¿Es 
necesario dar cuenta de la prueba? ¿Qué pasa cuando los actos son falsos, cuando se los enmascara para beneficio de un ser, un nombre, grupo o interés?

Como se observa desde los epígrafes, principios antiéticos han regido la historia de occidente, pero lo que el relato oficial no cuenta, lo grita la literatura y en ella la opción no se reduce al sufrimiento, aparecen la risa y la ironía como marcadores de consciencia, y otras voces, la de los excluidos, la de los desaparecidos, la de los fantasmas, y con ellos la sospecha de lo que han impuesto como verdad.

En Dar la muerte (2000), a propósito de Abraham, Derrida cuestiona: ¿cómo interpretar los secretos de la muerte? ¿Cómo entender lo indescifrable? ¿Quién está autorizado a reinterpretar la memoria? Todos de alguna forma somos la memoria olvidada, esto concede una herencia irrenunciable y obliga a una relectura del mundo, quizá a partir de la confesión, el arrepentimiento y el perdón. Por su parte, Jean-Luc Nancy hace un llamado a la ética de la convivialidad sobre la cual se basan las buenas intenciones; pero, qué modelo se tiene: "detrás de la palabra "convivialidad" hay un gran modelo antiguo y cristiano, que es de la hospitalidad. Ese es el modelo de la convivialidad. Ser capaz de abandonarse al otro. Que cualquier recién llegado pueda ser bienvenido" (Nancy, 2009, p. 105).

Aceptar al otro implica diversas dificultades, es renunciar a su dominio y aceptar la libre comunidad; el lugar común de todos los seres es la muerte, es lo que compartiremos, de allí que tanto para Derrida como para Nancy, este acontecimiento, cada vez único, cobra relevancia a nivel social y cultural. ¿Cómo se muere? ¿Cómo tratamos a los muertos cercanos? "Saber compartir la muerte es la gran cuestión, el gran secreto, tal vez, de todas las culturas. Una cultura fuerte es siempre la que sabe qué hacer con sus muertos" (Nancy, 2009, p. 107) El problema, dice Nancy (2009), es que "ya no somos ni cristianos ni revolucionarios" (p. 107).

¿Qué pasa con los muertos y con los vivos en Colombia? La historia oficial ha sido responsable de diversas subjetividades y secretos. La literatura una vez más abre la posibilidad de reparar y crear memoria, en ella son permitidas las representaciones prohibidas. Por esta razón, este texto busca detenerse en algunos problemas que plantea la novela La carroza de Bolivar (2012) del escritor Evelio José Rosero Diago; esta obra que no pretende ser una novela histórica, a pesar de las desastrosas y violentas herencias sociales y políticas, deja un margen a la esperanza, virtud que como bien lo diría María Zambrano, es lo único que no se puede perder; aquí es el pueblo 
el encargado de dar un giro a la lectura convencional de la historia, para significar su dignidad, para traer al presente la voz de los sin voz, para expresar que ya no se desea seguir padeciendo otros cien años de soledad.

Existen muchas historias por sanar, no es escandaloso afirmar que no tenemos una salud social ni cultural, cómo tenerla si hay ausencia de consciencia colectiva y autoconsciencia. En esta medida la literatura se convierte en una especie de medicina, remedio para mirar de otra forma, para hacer posible un nuevo ser desde una profunda introspección y evaluación, desde la educación sin privilegios de clase ni jerarquías dominantes. Así:

Si había que matar por un capricho, por un capricho se mataba. El sueño de la Gran Colombia era el sueño de sí mismo, de su poder. Delegaba la autoridad y la riqueza pública en militarotes burdos y en pensadores zafios, en los zalameros que no inquietaban su ambición, los mismos que a su ocaso hicieron la desgracia de Colombia, imitándolo como pequeños espejos donde la suerte los llamo (Rosero, 2012, p. 128).

Con base en esta realidad deseo abrir el debate teniendo en cuenta tres aspectos que sustento con base en la novela de Rosero y el pensamiento deconstructivista, relacionados con: la memoria y el dolor, el sujeto mítico y el sujeto colectivo.

\section{1. ¿Es posible definir qué es la memoria, el dolor y la deconstrucción?}

La memoria y el dolor son maestras, humanizan, están ligadas a la existencia, al ser. ¿Por qué nos falta memoria? ¿Por qué para aprender se sigue eligiendo la vía del dolor? Existen grandes maestros del dolor como Jesucristo y un sinnúmero de mártires. Deconstruir los conceptos de memoria y dolor exige leerlos de otra forma y empezar a abrir conciencia. ¿Por qué desde la deconstrucción? Esta postura filosófica invita a desmontar los discursos y sistemas de poder dominantes; más allá de las jerarquías y de la lógica binaria, ayuda a desvelar lo que la versión oficial oculta, la falsedad de la tradición, y ¿qué mejor forma de hacerlo que haciendo hablar a los que no hablan? Pero este no es un método, es una forma de crítica que produce quiebres 
a la representación del poder. Si se acude al Diccionario de la Real Academia de la Lengua Española (2012), se encuentran diversas acepciones:

Memoria: -Facultad psíquica por medio de la cual se retiene y recuerda el pasado; -Exposición de hechos, datos o motivos referentes a determinado asunto; -Relación de algunos acaecimientos particulares, que se escriben para ilustrar la historia. Dolor: -Sensación molesta y aflictiva de una parte del cuerpo por causa interior o exterior; -Sentimiento de pena y congoja. Deconstrucción: -Acción y efecto de deconstruir; -En Filosofía. Desmontaje de un concepto o de una construcción intelectual por medio de su análisis, mostrando así contradicciones y ambigüedades.

La tarea de definir es compleja y esa no es la pretensión; a lo mejor lo único que queda claro es lo que afirmara Witgestein cuando señaló que "existe en verdad lo inexpresable"; y en este juego del lenguaje y del transcurrir de los acontecimientos, la literatura, es y seguirá siendo huella auténtica e infinita.

La deconstrucción derridiana es un riesgo, es una forma de emprender el desmontaje de la gran infraestructura metafísica, aquella fundada en la visión logocéntrica. Derrida, indaga desde lo textos platónicos hasta los textos contemporáneos, desde lo que hay de indecible y de falso en las palabras, en la tradición que se expande a diversos países y culturas.

La deconstrucción irrumpe en un pensamiento de la escritura, como una escritura de la escritura, que por lo pronto obliga a otra lectura: no ya imantada a la comprensión hermenéutica del sentido que quiere-decir un discurso, sino atenta a la cara oculta de este (...) (Derrida, 1989a, p. 16).

Derrida sostiene que el pensamiento está fundado en premisas equivocadas, las publicaciones de De la gramatología (2008-1967), La escritura y la diferencia (1989b) y La voz y el fenómeno (1995), replantean la concepción que busca lo verdadero y ponen en la escena filosófica otros valores; su tesis es que no existe un significado válido y definitivo para los textos; tiemblan así los cimientos del logocentrismo. No es posible entonces una visión lineal o absoluta, no hay verdad sino pluralidad.

En La carroza de Bolivar se experimenta el terror, habla la voz ausente, se desmorona la máscara, salen a flote relatos que estaban encriptados; se visibilizan y testimonian trágicos acontecimientos ocurridos al suroccidente de Colombia 
en el siglo XIX, la imagen del llamado libertador Simón Bolívar se tambalea, él se deshace como dictador; el autor recupera la memoria de acontecimientos trágicos, genera otras lecturas del ser, del pasado y su repercusión social. La novela de Evelio reconstruye la memoria a través de la ficción que obliga a repensar el sujeto y en concreto el mito del héroe, la soledad y olvido del pueblo y también al espíritu exorcizador y colectivo de la fiesta. Pero, ¿por qué la sociedad crea falsos héroes? ¿Necesitamos de héroes?

Si el mundo se cimienta sobre la mentira, esto trae consecuencias nefastas para la salud individual y colectiva. Colombia padece una larga y trágica tradición de violencia, desigualdad y olvido. El pensamiento y la cultura están heridos y constantemente amenazados. Los muertos pasados no descansan, los fantasmas aparecen no solo en la memoria de sus seres queridos sino también en la piel de la ciudad, del campo, de las cosas... Aparecen en aquello que se quiere borrar; ¿qué es lo imborrable? Como palimpsesto, la memoria del dolor habla porque no es gratuita, nadie sufre por nada ni para nada. "Es la memoria de la verdad, que pugna por imponerse tarde o temprano. Corrigiendo el error histórico, denunciándolo, se corrige la ausencia de memoria, una de las principales causas de este presente social y político fundado en mentiras y asesinatos" (Rosero, 2012, p. 126).

La humanidad occidental tiene de fondo un tejido lleno de odios, de renuncias, de temores, una base patriarcal logocéntrica; Dios y el héroe se confunden y se elevan como autoridades incuestionables y éticamente son injustificables. Sin embargo, existe la paradoja, en la muerte está la vida, en el dolor el goce; es decir, trascender la lógica dual para dar desde el aparente no dar, dar amor desde el odio, ¿es esto posible? Quizá de esta forma sea entendible el comportamiento de personajes como Bolívar.

Pero, ¿por qué no nos recuerdan ustedes, Arcaín, Justo Pastor, esa Batalla de Bomboná que ganó Bolívar y le permitió entrar a Pasto? Ustedes, más que nadie, podrían ayudarnos a recordar lo que desde hace ciento cuarenta y cuatro años olvidamos, pueblo sin memoria. (Rosero, 2012, p. 142).

La carroza de Bolívar trae al lector en forma crítica algunos hechos del siglo XIX: la Batalla de Bomboná y la Navidad Negra, y la remembranza de los mismos en los años 60 del siglo XX. Entre las controversias que abre sobresale la reparación de las víctimas, este es uno de los problemas de salud pública tanto a nivel mundial como nacional y 
regional que puede abordarse desde diversas perspectivas. Recuperar la memoria del dolor del sur de Colombia es importante no solo para no repetir la historia, sino que también para no perpetuar como lo afirmara Hegel, el pensamiento de la conquista, la dialéctica del amo y el esclavo; su valor añadido es entender el desatroso presente, intentar sanar, reconciliar, cambiar. Transmutar la historia de la infamia y la mentira desde la inclusión, la no violencia, la equidad y la renuncia de la mentira.

La escritura despierta duelos inesperados, la mirada se transforma constantemente. La creación trabaja con la memoria, constituye un esfuerzo continuo de apropiarse de la ruina, ella es también, una pulsión de muerte. ¿Cuáles son los duelos? Evelio a través de sus personajes libera el dolor como ausencia y desconocimiento del otro; los muertos no desaparecen, el duelo es infinito, interminable, sin principio ni fin; queda la resonancia, el espectro. Los fantasmas son extraños porque no pertenecen al presente, son invisibles y por lo mismo son siempre alteridad de lo visible y, producen llamadas, ecos, recuerdos, creación.

En otra de las obras maestras de Rosero como en Los Ejércitos (2007), también irrumpe la memoria de la violencia, el desplazamiento y los desaparecidos.

\begin{abstract}
(...) No hace más de dos años había cerca de noventa familias, y con la presencia de la guerra -el narcotráfico y el ejército, guerrillas y paramilitares- solo permanecen unas dieciséis. Muchos murieron, los más debieron marcharse por fuerza: de aquí en adelante quién sabe cuántas familias irán a quedar, ¿quedamos nosotros?, aparto mis ojos del paisaje porque por primera vez no lo soporto, ha cambiado todo, hoy -pero no como se debe, digo yo, maldita sea. (Rosero, 2007, p. 61).
\end{abstract}

De igual manera manifiesta Rosero (2007):

La gente se olvida de la temible suerte que es cualquier desaparición, y hasta de la posible muerte del que desapareció. Es que toda la gente se olvida, señor, y en especial los jóvenes, que no tienen memoria ni siquiera para recordar el día de hoy; por eso son casi felices (p. 28). 
Además de las obras de Evelio José Rosero Diago ${ }^{1}$, autores contemporáneos como Héctor Abad Faciolince, también vuelven hacia la memoria del dolor; en El olvido que seremos (2007), por ejemplo, aparece la muerte del padre acontecida en 1987 a manos de los paramilitares ${ }^{2}$. Pero, el olvido no es del todo olvido, a pesar del caos y las distintas guerras que lo sustentan, a pesar de imponer una ley, una visión patriarcal, siempre queda algo diferente; lo esencial, el amor, lo compartido, lo construido, lo extrañado, lo que se revive, lo no divulgado, lo que no se puedo callar ni con la misma muerte.

Cuántas violencias y heridas absurdas, cuántas realidades que parecen no tener cura, y sin embargo la vida no comienza y no termina, la vida como escritura se convierte en el juego de la videncia, juego que está en manos de los artistas, son ellos los que asumen la experiencia liberadora del farmacón; crear es desear, es salir de la caverna, es ver, ver sin ver; es bordar la escritura que se creía perdida, es trazar la esperanza sin tiranía ni hostilidad. Este ver en la creación se relaciona con la memoria, funciona como un mecanismo de ruina, ¿qué es aquello que no se puede recordar?, ¿qué es lo que se recuerda? Siempre vendrán fragmentos, instantes, trazas, trazos; tener memoria es de alguna forma perderla; la memoria es una pulsión de muerte, es un juego; la ruina existe desde el comienzo de la escritura, desde el comienzo de la imagen.

Tanto en Derrida (2001) como en Rosero, la memoria es un juego de velos, es una especie de abismo desde el cual se escribe, se pinta y se crea; en la escritura siempre hay un requerimiento de interpretación, una llamada. Pero, los sentidos como la vista son insuficientes, ¿qué es lo que en ellos no está? Siempre hay una interrupción de órdenes entre lo visto y el ver, los sentidos se cruzan; hay una heterogeneidad entre lo dado y el darse. No es posible en la historia de los velos un significado único y estable, la única posibilidad es el juego, en él el hombre ha inventado reglas, ha puesto límites, vale la pena preguntar, ¿por qué predomina el nefasto juego de la muerte?

1 Evelio José Rosero Diago, en el 2014 el Ministerio de Cultura reconoce a La carroza de Bolívar como la mejor novela publicada los últimos dos años. En la actualidad es uno de los artistas literarios más reconocidos internacionalmente, con su novela Los Ejércitos fue ganador en el 2006 del II Premio Tusquets de Novela, y por la misma obra, en el 2009 le fue concedido por el diario británico The Independente el prestigioso premio Independent Foreign Fiction Prize. Previamente había ganado otros premios: Premio Iberoamericano de Libro de Cuentos Netzahualcóyotl, México, 1982, y en ese mismo año el Premio Internacional de Novela Breve Valencia Editores, en Colombia.

2 En este año 2015 se acaba de estrenar el documental homenaje a esta víctima: Carta a una sombra dirigida por Daniela Abad y Miguel Salazar. 
Tristemente la muerte sigue siendo protagonista; se requiere humanizar, brindar otra mirada del dolor y de las tragedias, reconstruir, descubrir la verdad; para abrir conciencia Evelio narra lo que ocurría en la ciudad de Pasto en el siglo XIX, indaga en el fondo mismo de las causas del olvido y las miserias actuales. ¿Qué sucede con la verdad? ¿Qué le sucede al que intenta decirla?

Porque después de esas últimas clases, de subrepticio desafío (donde la batalla de Bomboná confirmaba ni más ni menos que la ignominia de Bolívar, donde la Navidad Negra, en Pasto, instauraba la barbarie a nombre de Bolívar) que Arcaín Chivo debió abandonar la cátedra de Historia, primero de una muy directa patada por arte de rectoría, y después de otras muy concretas patadas por arte de encapuchados que amedrentaron definitivamente al ya de por sí amedrentado catedrático Chivo (...) Jamás imagino que las directivas y los mismos universitarios de Pasto, pastusos la mayoría de ellos, oriundos de diferentes pueblos de Nariño, justamente donde Bolívar se esmeró en venganzas y barbaries, resultaron en desacuerdo con la verdad de la historia, y no corroboraron por lo menos una sola de sus razones -y las aseveraciones de Carlos Marx, de José Rafael Sañudo-, y, peor aún, se escandalizarán, lo expulsaron (Rosero, 2012, p. 169).

Lo que pasa en la cultura deja su huella, aunque se la quiera borrar, permanece. La novela brinda: una nueva y reveladora visión de la guerra de Bomboná, muestra la falsedad de la historia impuesta y la falsedad del llamado libertador, e incluso deja en la escena la sospechosa de sus victorias. De esta forma Evelio no solo resucita el pasado sino que lo repara, dignifica a los muertos y a las víctimas, no olvida a los inocentes acribillados en la llamada Navidad Negra; esta masacre que aún duele, sangre que grita en Pasto desde finales de 1882, la muerte no descansa si se oculta, porque el dolor crea enfermedad, no es ilógico decir que hace parte de los actuales desastres como la violencia, el crimen, la miseria. Este es un ejemplo de las primeras barbaries oficiales ocurridas en Colombia; ¿es posible transformas las crueldades en algo distinto?, corresponde a cada pueblo cambiar su historia, transformar el odio y el olvido implica deconstruir y construir nuevos relatos.

La novela desentraña huellas, siempre hay en la huella una instancia de memoria, algo que no es ella, pero que la constituye; la huella trae un cierto diferimiento del 
tiempo, trae la diferencia. No es reconciliable con la presencia, si está aquí es porque algo no está presente; el inconsciente mismo está plagado de huellas.

La huella es la diferencia que abre el aparecer y la significación. Articulando lo viviente sobre lo no viviente en general, origen de toda repetición, origen de la idealidad, ella no es más ideal que real, más inteligible que sensible, más una significación transparente que una energía opaca, y ningún concepto de la metafísica puede describirla (Derrida, 1989, pp. 84-85).

Decir huella implica diferir en el tiempo, ir a un porvenir y a otras huellas. En esa relación la huella hace un llamado a más sentidos por venir, pero en la donación de sentido, existe un movimiento de borradura. Para Derrida, el pensamiento de la huella nunca se confundirá con una fenomenología de la escritura; leer y escribir son articulaciones en un tiempo y espacio desbordados. Las huellas en La carroza de Bolívar, no son algo resuelto, son complejas, propician movimiento, reconstrucción, irrupción, desacomodación. No existe habla ni escritura plena; la huella está siempre siendo, su problemática es la de la diferencia. Para Derrida, las palabras y conceptos solo adquieren sentido a través de encadenamientos de diferencias; el lenguaje de la huella solo se puede explicar desde el interior de la historia, pero no hay justificación definitiva.

La palabra huella debe hacer referencia por sí misma a un cierto número de discursos contemporáneos con cuya fuerza esperamos contar. No se trata de que aceptemos la totalidad de los mismos. Pero la palabra huella establece con ellos la comunicación que nos parece más segura y nos permite economizar los desarrollos que han demostrado su eficacia (Derrida, 1989, p. 91).

En la huella derridiana todos los dualismos se borran. Es pertinente resaltar que toda experiencia de sensibilidad está más allá de los sentidos, siempre hay un algo más, existe un suplemento. El movimiento de la huella es el de la creación y el pensamiento; el arte dentro de esta visión es apertura de espacios de indagación, de juego, y a la vez es interrupción de sentido, experiencia imprevisible; siempre hay un invisible en lo visible, un porvenir sorpresivo, en eso quizá esta esa otra magia. La magia de la escritura como interrupción que no cesa, gracias también al grito de sus silencios, a sus abismos, vacíos y secretos, y a esos hilos que van tejiendo y destejiendo la madeja llamada escritura, texto, creación. 
Para Rosero, igual como lo asume Derrida, el pasado no puede ser vivido bajo la forma originaria y modificada de la presencia; emprende la deconstrucción de la presencia a favor de la reconstrucción de la conciencia. Antes de cualquier antes, es preciso pensar la huella sin oposición, pensarla como el archifenómeno de la memoria. Derrida (2008) propone la noción de archiescritura como la primera posibilidad del habla, y luego de la "grafía". Desde Platón, Rousseau, Saussure y Lévi Strauss, se ha favorecido al habla sobre la escritura, este logocentrismo ha significado la verdad, la razón y la ley, el origen y el centro. Así se ha instaurado durante siglos la metafísica de la presencia, en cuyo sentido trascendental aparece Dios; la escritura en dicha concepción está asediada por la ausencia, es vista como el anhelo de la presencia. Derrida (2008), en De la gramatología (2008), no solo deconstruye tal tradición, sino que propone, así como lo hace la filosofía de Nietzsche, unos valores nuevos, de la diferencia, la huella, el otro, el porvenir. Así el lenguaje es en Derrida como en Rosero, una infinitud de huellas y diferencias entrelazadas; por lo tanto, según el filósofo argelino francés, decir habla o escritura es inadecuado, de allí que él prefiera el término de archiescritura.

La fuerza y pertinencia de la literatura como archiescritura son esenciales cuando que se intenta encontrar la paz, su territorio incluye saberes y voces olvidadas; de esta forma no solo se convierte en fuente de memoria sino también en una forma de conciencia. Es importante que el dolor se profundice, esto requiere reconocer en Colombia a las innumerables víctimas de las distintas guerras generadas no solo por la guerrilla de las FARC, el narcotráfico y los paramilitares, sino aquellas generadas por los políticos y también por la indiferencia de la gente. De allí que no sea casual que Rosero destaque con la muerte de su protagonista, un médico ginecólogo, la compleja trama de la violencia y toda la maquinaria que se arma para intentar borrar la memoria del dolor. Su novela expresa la contradicción de una guerrilla que defiende la figura icónica del héroe y evita que se conozca la verdad que inevitablemente delataría sus desastres, pues lo considera un líder incuestionable, intocable; era necesario recurrir al crimen del médico, personaje que deconstruye a Bolívar. Vale la pena preguntar qué visión del poder es la que impera en unos y otros mandos; la obra sugiere que quizá sea posible empezar a construir relaciones humanas no verticales y jerárquicas sino horizontales.

La carroza de Bolívar es un universo de huellas que se conjugan para rechazar las convencionales representaciones del héroe y del poder; el autor produce diversos 
quiebres del sujeto individual y resalta al pueblo, y a sus voces ocultas, voces testigos de la masacre, voces que no se pueden olvidar si en verdad se quiere sanar a esta parte de la sociedad. De esta forma, Rosero toma una postura evaluadora de la cruda realidad que aconteció en San Juan de Pasto; con ironía hace un llamado para recuperar la verdad, la memoria y el dolor; se deduce que este último debe servir para humanizar, para reparar, para rendir una especie de homenaje a la dignidad de los inocentes, a los valientes que resistieron a la miseria y el engaño. Frente al intento de borradura de los poderes dominantes, una vez más la literatura se convierte en la voz del pueblo indefenso; de allí que salten en las páginas los inconformismos y las críticas de los personajes a la carencia de memoria y a la manipulación de la historia: "ya nadie recuerda en Pasto, Justo Pastor. Los han incorporado eficazmente a la buena historia de Colombia, con toda su retahíla de héroes y ángeles" (Rosero, 2012, p. 121).

La novela además desmiente otros hechos, por ejemplo el realismo monárquico de los pueblos del sur, y recuerda a algunos de los primeros mártires de la República. A su vez Evelio José incluye datos publicados anteriormente por la historiadora Lydia Inés Muñoz Cordero, quien ilustra el realismo del pueblo de Pasto (1996) y también el papel de los republicanos, especialmente destaca a los personajes femeninos (Mujeres del sur en la independencia de Nueva Granada, 2011).

Eran tan "realistas" los pastusos que la primera rebelión del mundo contra el rey español ocurrió en su provincia, muchísimo antes del "grito de independencia" de 1810. Fue en 1781: veintinueve años antes. Y fue un levantamiento popular por los nuevos impuestos reales, rebelión que acabó con la vida del cobrador de impuestos, el español Ignacio Peredo, a manos del indio Naspirán. Hubo también otra revuelta contra los reales decretos, de proporciones mayores a muchos de los que ha enaltecido la historia; esta segunda ocurrió veinte años después de la primera, y nueve años antes del grito oficial de independencia: sucedió en Túquerres, cerca de Pasto, y cobró la vida de los hermanos Clavijo, comerciantes acaudalados, representantes del rey en el recaudo de impuestos. Otra vez los indios y montañeses fueron protagonistas: su grito de rebeldía hizo callar al párroco encargado de leer el decreto en plena misa mayor, un domingo 18 de mayo: dos mujeres indígenas, Manuela Cumbal y Francisca Aucu, le arrebataron de las manos el papel del decreto, y al grito de abajo el mal gobierno lo pisotearon (Rosero, 2012, p. 188). 
¿Por qué seguir callando? ¿Es posible que la cultura recupere su salud si olvida sus tragedias? ¿Los muertos aunque están muertos hablan? La novela de Evelio contribuye a crear una nueva lectura de lo ocurrido en el sur de Colombia y su repercusión en la salud colectiva.

\section{Sujeto mítico}

Es preciso deconstruir a los reconocidos héroes y libertadores de la patria. La obra de Rosero Diago visibiliza y desprestigia al sujeto mítico a la figura rodeada de extraordinaria estima y fama, de allí que desvele las máscaras del libertador llamado en la obra: "el falso héroe", "Napoleón de las retiradas". Bolívar es el error del paradigma que es necesario desocultar no solo en Colombia sino en América Latina, en donde han predominado poderes y egos personales más que el bienestar del pueblo. "El grito de la independencia era menos que un grito a medias, era un gritito de la nobleza criolla, burgueses que a toda costa querían aprovechar de la tajada. Ninguno pensaba en su pueblo americano y otras lunadas sino en su propia hacienda, señores" (p. 170).

Para descentrar a aquel ser que se ha engrandecido a lo largo de la historia, La carroza de Bolivar abre la sospecha y da lugar a otras lecturas del reconocido "héroe", con el fin de ayudar a desentrañar la verdad. ¿Qué tan valiente era? ¿Realmente luchó por los derechos humanos? ¿Cuál era su concepción de patria, de libertad, de humanidad? Traer a la memoria hechos nefastos como la olvidada masacre del sur, no solo pone en tela de juicio al sujeto considerado libertador, sino que fundamentalmente abre el debate sobre las bases desde donde se eleva la historia. De allí que una forma de reparar el dolor del pasado sea hacer visible la verdad y sus consecuencias, y si esto no es posible por el tiempo o por el espacio, sí lo es a nivel simbólico y ficcional, de esta forma se contribuye a acrecentar el nivel de conciencia individual y colectiva. Sospechar por ejemplo del binomio verdad-mentira, héroe-antihéroe; dudar de las supuestas seguridades históricas obliga a una lectura de la realidad más allá del sujeto representacional.

Y el grandísimo ejemplo de su primer gobernante fue nefasto: de Bolívar provienen las pequeñas y grandes dictaduras, $y$ todas estas adversas y corruptas administraciones que los más cínicos han dado en llamar "países en vía de desarrollo"; los indios y campesinos siguen en las mismas, y a su miseria proverbial se suman ahora los obreros de las ciudades (Rosero, 2012, p. 171). 
Si el ser considerado héroe es un ser falso, si su virtud no es más que un engaño, es entendible que desafortunadamente esta es la raíz de una cantidad de desastres. ¿Qué trae como consecuencia la mentira, la violencia, la injusticia? Más mentira, violencia, injusticia...

Tal como lo señalara William Ospina (2013) en Pa que se acabe la vaina (2013), Bolívar en el dramático momento de las guerras de independencia no se enfrentó al poder clerical, sino que permitió que su educación se abriera camino en la naciente república. Además, señala que este sujeto, sinónimo de ilustración y comprensión, en subconflicto con Piar en el Orinoco y Agualongo en el sur: "terminó resolviendo de un modo bárbaro dos de los problemas centrales de su tiempo" (Ospina, 2013, p. 21).

Agualongo fue uno de los primeros en comprender que al pueblo indígena le iba peor con los criollos que con los españoles, estos últimos tenían una legislación más benévola con los nativos. Bolívar sacrificó al indígena, desde allí señala Ospina, viene una gran deuda de respeto y dignidad que aún está pendiente.

Vale la pena preguntar por qué existen tantos dogmatismos y lealtades absurdas; la rigidez clasista y el engrandecimiento de una figura que en realidad no fue un líder democrático sino un ser capaz de excluir, despreciar y aniquilar a muchos. Si el país no se libera de la base colonial que lo inaugura es claro que está condenado a reproducir falsos esquemas de libertad, donde las trampas que impone el poder siguen manteniendo privilegios para pocos; entonces es entendible que la ley existente perpetúe poderes corruptos. Desde aquí viene el olvido de la memoria, el desprestigio de saberes ancestrales, la desaparición del pueblo, el ocultamiento de su voz, el racismo, la demagogia y todo tipo de inequidades, también la incredulidad y el escepticismo frente a quienes gobiernan.

Hay mucho por sanar, un país como Colombia es un país herido, predominan todo tipo de arbitrariedades, la palabra carece de valor, el indígena y el campesino son despreciados y tratados injustamente; la historia que relatan los distintos poderes se ha convertido en una forma de hostilidad y no de hospitalidad. La tiranía de los diversos poderes mata y manipula las ideas, fomenta la ignorancia, la intimidación y el chantaje. La verdad se etiqueta, se disfraza, se vende para perpetuar la inequidad y la larga tradición de servidumbre y sumisión de la gente. Cuántas masacres y guerras olvidadas, cuántos sujetos impostores se convierten en héroes, cuánta intolerancia frente al honesto. Ospina (2013) dice: "y no puede extrañarnos que de un modo 
creciente Colombia se haya convertido en una fábrica de monstruos" (p. 102). Fabrica de muerte, de chantajes, mentiras y mentiras.

Exterminar la memoria es una forma de perpetuar la infamia, la violencia, la pobreza, el olvido y el dominio de poderes corruptos; es una forma de permitir que unos pocos se sigan considerando los dueños de país. También es una forma de trivializar los hechos y restar importancia a la conciencia histórica. Rosero (2012) en su novela recuerda que: "Bolívar dio el desastroso ejemplo que se convertiría con el tiempo en cultura política colombiana" (p. 128). Una cultura de corrupción, de oportunismo, de egoísmo; manifestación de un poder mediocre y nefasto; sobre realidad la literatura se eleva como la voz de los sin voz; recupera la memoria, forma un espíritu auténtico y crítico.

¿Qué tal hablar de libertades cuando planeaba coronarse Monarca de los Andes? Alentaba los progresos de la república, pero tras bambalinas derrumbaba lo que en público construía; intrigaba, enredaba, disimulaba, para que otra vez los de su corte hicieran eco de su propósito real, la dictadura que promulgaba como si a él jamás se le hubiese pasado por la cabeza. Ocurrió en incontables ocasiones. Solo en eso se ocupaba, mientras demoraba las prioridades vitales de la nueva república: la educación, la industria, que constituyen la independencia real de un país, no la independencia de un amo que se reemplaza por otro (Rosero, 2012, pp. 127-128).

El poder enceguece y transforma negativamente cualquier valor; si la mentira se impone como verdad, si la muerte calla al justo, si la vida no es un derecho, es necesario cambiar. La obra por ejemplo, descubre a un Bolívar egocéntrico, orgulloso, desleal, abusador de mujeres, avaro, cobarde, pero sí muy hábil para hacerse propaganda como el mejor; desde el siglo XIX los políticos hacían marketing, la retórica griega se renovaba para seguir cumpliendo sus propósitos: convencer maquiavélicamente, no importa si en el fondo todo no es más que una vil mentira. Entre los numerosos ejemplos que sustentan en la novela el quiebre del pretendido héroe está lo que le ocurrió al señor Santacruz, quien le entregó a Bolívar suficiente oro a cambio de salvaguardar la honra de su hija de 13 años, Chepita del Carmen; pero, él hizo lo contrario y la devolvió preñada: "la uso de inmediato, y la siguió usando al descampado durante toda esa marcha forzada hasta las puertas de Quito” (Rosero, 2012, p. 204). 
Quien se atrevía a criticar al líder tendría que pagar las consecuencias, un ejemplo de esto es lo que le ocurre al médico de la novela que cae asesinado por el delito de pretender desmitificarlo

Doctor -le preguntó Puelles encarándolo, y aferraba uno de sus brazos-, ¿jpor qué no deja en paz a Bolívar? Suspenda esa vaina y todo se arregla, el doctor manoteó el aire, bebió, no se puede dejar en paz a los muertos si los muertos no dejan en paz a los vivos -sentenció (...) (Rosero, 2012, pp. 308-309).

Los primeros en advertir sobre el falso héroe son Marx (1974) y Sañudo (1925):

Era Sañudo el primer historiador del país y acaso del continente -como solía resaltar con vehemencia el doctor Proceso- que se atrevió a descifrar de manera irrefutable la catadura histórica de Bolívar, sin falsas emociones patrioteras, sin depender de la corte exagerada de halagos (ojos ciegos y oídos sordos) que la gran mayoría de historiadores concede a Bolívar como una tradición desde su muerte (Rosero, 2012, p. 59).

Este atrevimiento de Sañudo, le trajo graves consecuencias que aparecen en la novela:

\begin{abstract}
A Sañudo esto "le significó el desdén y la condena de los suyos, no solo del país sino de sus mismos coterráneos, que acusaron "profunda sorpresa e indignación por su nefasto libelo". En Manizales pidieron a gritos que lo llevaran a la horca, en Bogotá se le declaró traidor a la patria, la Academia de historia de Colombia lo llamó hijo ingrato, la Sociedad Bolivariana volvió a llamarlo hijo, pero indigno de Colombia, y si su obra halló en su alborada uno que otro intérprete medianamente serio, todos, sin excepción, lo comentaron con absoluto pánico, y uno de ellos, a pesar de reconocer que Sañudo no calumniaba y que cada una de sus aseveraciones estaba perfectamente fundamentada, no dudó en calificarlo de pastuso retrógrado, teólogo hirsuto, prosador enrevesado y vejete casuístico (Rosero, 2012, pp. 59-60).
\end{abstract}

Efectivamente Sañudo publicó Estudio sobre la vida de Bolívar, desde la introducción señala la directriz que lo motiva, la verdad; toma las palabras de Ciceron para decir que "la Historia es lux veritatis, vita memoriae, magistra vitae" (Sañudo, 1925, p. I); 
tiene claro que estas virtudes servirán para guiar a las naciones. Reconoce cómo en el departamento de Nariño, que a pesar de tener gran patrimonio humano, en su pobreza material ha influido la guerra de Independencia y el desamparo del gobierno. Recuerda el dolor que define a la humanidad, desde la Pasión de Cristo, hasta las desgracias de los pueblos. Con erudición y lucidez argumenta diversas teorías de la historia, advirtiendo el peligro de que existan partidos permanentes porque como consecuencia se tendría el sectarismo, la falta de conciencia y moral, y la guerra.

Para el historiador tanto el bien como el mal son fecundos y traen distintas repercusiones sociales. Pero, cuando la verdad no es la que sostiene la historia, es cuando aparece nuevamente el dogma del pecado. “(...) con pecar Adán, toda la humanidad está herida de muerte, y llena de desdichas y aflicciones" (Sañudo, 1925, p. 8) ¿Qué es lo que se transfiere a sus descendientes? Si esto se lleva al plano de los llamados héroes de la patria, si seres como Bolívar no fueron dignos, es entendible el por qué Colombia siga herida de muerte, y no es de asombrar que a ciudades que intentaron denunciar la verdad como San Juan de Pasto, se las haya condenado y relegado social y económicamente.

Se ha hecho de Bolívar un mito; de modo que el concepto vulgar que de él se tiene no corresponde a la realidad. Atribuyéndosele todo género de virtudes y talentos; y está tan poco estudiada su vida a la lumbre de un justo criterio, que como a un héroe de leyenda, dándosele dones maravillosos y toda suerte de bondad (Sañudo, 1925, p. 2).

En plazas y calles se representa su estatua como sinónimo de grandeza y libertad, pero $\dot{i}$ su leyenda es cierta?

En el capítulo V del libro sobre Bolívar, Sañudo trata sobre la Batalla de Bomboná y los castigos atroces que le imponen a la ciudad de Pasto, es decir, la historia de este lugar de Colombia, infortunadamente tiene mucho que ver con la biografía de un hombre público, el jefe de la nación, caracterizado por su crueldad:

"Así formado el campo realista, pasadas las tres de la tarde, el 7 de abril, que era Domingo de Pascua Florida, principió el combate llamado de Bomboná por los republicanos (...)" (1925, pp. 110-111) Las cifras de las bajas producidas en el campo de batalla se disfrazan y manipulan a favor de Bolívar, sin embargo, uno de sus 
hombres, García, le dice a través de un oficio que la batalla "no causo a Colombia otra ventaja que el llanto y confusión" (1925, p. 111), de esta forma le solicitó que retrocediera en sus planes de guerra, pero esto no fue posible. García al devolverle las banderas capturadas le dice en tono irónico: "yo no quiero conservar un trofeo que empaña las glorias de dos batallones, de los cuales se puede decir que, si fue fácil destruirlos, ha sido imposible vencerlos" (Sañudo, 1925, pp. 112-113) Bolívar no entendió y transmitió estas palabras como una certeza de triunfo, de esta suerte los historiadores de América narraron la victoria de Bolívar en Bomboná, pero Sañudo expone suficientes razones para demostrar lo contrario. Sin embargo este fallido vencimiento del "libertador" resulto ser muy caro para el pueblo que posteriormente padeció una Navidad infernal: "la matanza de hombres, mujeres y niños se hizo aunque se acogían a las iglesias; y las calles quedaron cubiertas de los cadáveres de los habitantes" (1925, p. 127). Con esta cruda realidad se puso fin a la insurrección del pueblo y se tergiversó lo que ocurrió, estigmatizando a la ciudad de Pasto como enemiga de la República y reduciédola a ruina, dolor y olvido.

Para Marx (1858), Bolívar fue un dictador cobarde, brutal y miserable, así lo afirma en diversos documentos (carta de Marx a Engels de febrero de 1858); lo consideraba un mito, propio de la fantasía popular. Lo describe como un ser desleal, no solo por la entrega del general Miranda, sino porque esa doble moral lo acompañaría siempre. Marx recuerda por ejemplo, que en la victoria de Santa Marta, permitió que la ciudad fuera saqueada por sus soldados; en la batalla de Valencia, abandonó a sus compañeros y no les concedió ningún auxilio, etc.

Según Roberto Fernández Retamar (1976) existe la leyenda negra que se origina por la cantidad de crímenes cometidos en América Latina por los conquistadores españoles; sin embargo, en las guerras de conquista, la crueldad y la muerte violenta son protagonistas en ambos bandos: el de España y el las tropas de Bolívar.

En esta ocasión es la ficción de Rosero la que desmitifica al héroe; Bolívar se descubre por ejemplo como un dictador que propicia en el sur la masacre de la Navidad Negra, un líder que miente e impone trampas a través de los decretos para seguir explotando al pueblo:

Bolívar había llegado a Pasto nueve días después de efectuada su Navidad de la Muerte, el 2 de enero de 1823, y empezó de inmediato: dio un decreto de confiscación de bienes, impuso una contribución de 30.000 pesos y 2.500 caballos, 
“que la saqueada Pasto no podía pagar". Las propiedades de los pastusos se mandaron a repartir entre los militares de la república. (...) ¿Cómo no iba a continuar la rebelión, empezando por los indios? ¿Qué clase de libertador era ese, que solo daba instrucciones para la ruina? (Rosero, 2012, pp. 227-228).

Por todo lo anterior es más que entendible la reacción atibolivarianista emprendida por el indígena, Agustín Agualongo.

\section{Sujeto colectivo}

Gracias al desenmascaramiento de la mentira que envuelve al mítico héroe independentista Simón Bolívar, el pueblo logra dignificar a sus víctimas y reconstruir la vida a través de la ironía vitalista permitida en la Fiesta de Blancos y Negros; sin que esto signifique olvidar su historia sino más bien reconstruir al sujeto mítico desde el carnaval, la risa y la fiesta. De allí que la novela de Evelio tenga como escenario la fiesta; teniendo como contexto la década de los años 60, los personajes expresan el sanguinario pasado que se ha intentado olvidar, utilizan como símbolo de ironía una carroza sobre Bolívar; una carroza que aunque las fuerzas oscuras del poder la quieran destruir, realmente no desaparece, porque el lector, la revive para poder entender el fondo de historia y dolor del sur.

El médico protagonista decide disfrazarse de gorila y aunque su vida personal está casi rota, insiste valientemente en desocultar a Bolívar; pero su broma termina cobrando además de la vida de su esposa, la suya propia;

Primavera Pinzón desaparecía de la tierra, víctima inocente de una broma más inocente todavía, y la noticia de su broma no solo echaría a volar por la ciudad sino que se adueñaría del país entero y a lo mejor del mundo, no es muy frecuente que un hombre mate a su mujer con un disfraz de simio a la hora de despertar (Rosero, 2012, p. 31).

Gracias al carnaval se recupera la memoria desde una visión vitalista que contribuye a la creación de una salud colectiva; él traduce la memoria y el dolor, ayuda a purificar la infamia reconstruyendo y reconciliando su propia historia. Esta es una forma de exorcizar olvidos y penas, la fiesta permite reanudar diálogos y conversaciones, 
crear relatos incluyentes, dignificar y humanizar a la sociedad. El pueblo responde con la fiesta no superficialmente, sino como una forma de trascendencia de sus propias tragedias y olvidos; crea la hospitalidad sin hostilidad para permitirse limpiar, renacer y hacer hablar a aquellos que no han tenido voz en la historia de Colombia.

En la manifestación colectiva popular del Carnaval, los muertos del pasado y sus herederos, piden que se cuente la verdadera historia. No importa si haya que mostrar "nuestra memoria a retazos" (Rosero, 2012, p. 120). Aunque se lo intente callar, el pueblo reacciona, la sabiduría popular habla; la existencia de la Fiesta de Blancos y Negros es una admirable respuesta a la manipulación oficial y extraoficial; "la carroza" "que era una sola broma perpetua, donde vivieron y murieron riéndose de sí mismos sus ancestros, en ese país suyo, que también era otra broma atroz pero broma al fin..." (Rosero, 2012, p. 14).

El profesor Jorge Verdugo Ponce (2013) en Carnaval y sociedad anómica colombiana en La carroza de Bolívar de Evelio José Rosero Diago (2013), destaca cómo la visión carnavalizada revela la memoria oculta, la existencia de un Estado y una sociedad regida por una normatividad desprestigiada que contribuye a la desinstitucionalización. Para Verdugo (2013), el autor adopta una postura ideológica suprapartidista en su evaluación de la realidad colombiana; en la obra el carnaval permite ciertas libertades como las asumidas por el médico que pretende recuperar lo perdido y desenmascarar al impostor.

Pero, no se trata solo del disfraz de gorila, esta máscara le ayuda a transgredir las reglas, pretendiendo una forma de aceptación familiar; este recurso se presenta en los inicios del carnaval, justo el día de inocentes, donde el agua se utiliza como material purificador. Paralelo a este acontecimiento su disfraz le permite entrar en contacto con los artesanos, y descubrir la creación de la carroza; uno de los personajes guarda parecido con Bolívar, el médico simio, les convence para que la figura se convierta en "el mal llamado libertador". La carroza desfilará el principal día del carnaval de Blancos y Negros, así se muestra la falsedad de las epopeyas del sur.

La ironía del personaje de la carroza se convierte en el secreto que grita; de allí que Agualongo y Sañudo ayudan a perfilar el sentido profundo de esta osadía; pero la ley reacciona, no es posible permitir que se desgarre la historia oficial del héroe. Sin embargo, el pueblo es sabio y se libera del orden y el dogma del poder corrupto; 
utilizando el símbolo desde lo cómico, aprende a disfrutar y a reír, trasciende la tragedia poniendo "el mundo al revés", virtud estudiada por Umberto Eco, Carnaval (1989).

Sobre el carnaval existen distintos aportes de autores clásicos y estudios sobre ellos como los relacionados con Mijail Bajtin, La fiesta del tiempo destructor y regenerador, una lectura de "Carnaval y Literatura: sobre la Teoría de la Novela y la cultura de la risa" de Mijail Bajtin de Carlos Patiño Millán (2010) y Bajtin y la teoría de la cultura (2012); estas investigaciones además de los aportes estrictamente literarios, involucran al pensamiento y la sociedad incluyendo aspectos fenomenológicos importantes como: el drama del héroe, la verdad, la risa, el carnaval, el escándalo, la subversión, el cuerpo. Desde la Edad Media los elementos del carnaval como el humor y la ironía poseían un carácter ritual que contribuía a relativizar el poder. En esta medida el pueblo como sujeto colectivo, decostruye la imagen, se burla de los opresores, manifiesta su nivel de conciencia; lo trágico y lo cómico se confunden, la sociedad necesita expresar su dolor, pero también reírse de quienes lo han propiciado. La fiesta permite no olvidar la memoria y manifiesta la grandeza de un pueblo capaz de purificar su pasado desde la recreación festiva de los hechos y la acción festiva de la vida.

Bajtín y muchos de sus comentaristas han tendido a describir el carnaval como una especie de Edén del Renacimiento desde el cual el burgués moderno ha caído en la representación en un proceso histórico unidireccional. Pero yo sostendré aquí que el carnaval es también un concepto y una práctica que constituyen una alternativa a la representación y no solo un predecesor de esta. (Jefferson, 2012).

El carnaval logra la igualdad, es una forma de resistencia a todo dominio, desestructura las jerarquías, incluye las diferencias, rompe fronteras, desoculta. En el cuerpo carnavalesco sobresalen los excesos, los defectos, la animalidad, no existe el sentido de pertenencia. Por esta razón, el dolor y la muerte ya no se leen como grandes desastres; la tragedia se disemina, se transforma, la cultura herida se convierte en valor diferente. El pueblo es capaz de regenerarse a través de la alegría, de esta forma dignifica su desmedido sufrimiento.

El poder de la risa une a la sociedad y dimensiona su cuerpo colectivo hacia la fuerza vital del placer; el cuerpo se convierte en texto, en escritura carnavalizada; se borran los sujetos y los objetos, se supera la doxa con la esperanza de una transformación esencial que despierte conciencia y altere el orden opresor. En la misma medida El origen de la tragedia (1981) de Nietzsche aporta las claves para una lectura deconstructivista 
desde la visión dionisiaca de la tragedia (griega) y cómo el hombre valora su propia existencia a través de la embriaguez que se manifiesta en la fiesta. "Las fiestas de Dioniso no solo establecen un pacto entre los hombres, también reconcilian al ser humano con la naturaleza" (Nietzsche, 1981, p. 232). La existencia del pueblo, señala el filósofo alemán, es infinitamente sensible, él está capacitado para el sufrimiento y para el goce; su dolor viene de la separación de lo humano y lo divino, pero, su inclinación es hacia la vida, esto justifica el por qué en todas partes se infiltre Dioniso, dios de la fiesta y la embriaguez, y con él la aniquilación de las barreras y los límites habituales de la existencia.

Umberto Eco (1989), define semióticamente el carnaval y su relación con lo cómico; de igual modo, analiza el fenómeno de lo trágico y su relación con la violación de una regla, una ley, proponiendo una nueva lectura del héroe y la máscara que animaliza. Frente al velamiento de la verdad el pueblo ridiculiza el orden impuesto y propone un desorden; el sufrimiento se transfigura en fiesta y en triunfo de la vida.

La carroza de Bolivar permite la llegada del otro como acontecimiento que deconstruye todo concepto de hegemonía y homogeneidad. La lengua no se reduce a Uno, a una identidad, raíz, uniformidad o pureza; existe su irreductibilidad, es decir, ella manifiesta la "expropiación" que siempre ha existido (Cixous/Derrida, Lengua por venir, 2004); ; existe más de una lengua en cada ser humano. La filosofía de Derrida y la obra de Rosero, son afirmación del otro y lo otro, contexto del respeto infinito, alteridad en donde el otro es irrreductible y, también hospitalidad incondicional. Este es el relato por venir, el gesto de leer y reescribir; la lengua literaria propicia la consciencia por venir, renuncia a la dominación, reconstruye la verdad y el respeto al otro; la novela de Evelio brinda esa hospitalidad casi perdida y se aleja de la manipulación mediática de la presencia y la representación. La responsabilidad es incalculable ante la memoria, las herencias, la historia y ante todos los presupuestos, imposiciones, sedimentos, más o menos legibles de la existencia. Quizá no todo está perdido y es posible reinventar otros relatos.

Para Derrida los que cultivan la escritura, o cierto tipo de palabra, refinan el movimiento de dominio, de apropiación y de deseo. Sin embargo, esto no implica que se olvide que en cierta forma toda cultura es colonial, la lengua impone el más fuerte, incluso dentro de sí misma; pero, la lengua no es algo autónomo, ni es propiedad de un alguien, está en cada ser dar los giros necesarios para hacer de ella una oportunidad de reinvención de sí y de la historia. Decontruir la memoria, recuperar las huellas 
del pueblo, los rastros que se cruzan para desocultar y reinventar una historia que transgreda la tragedia del pueblo y del héroe; escribir para significar la diferencia y hacer del dolor una oportunidad de transformación, aprender de los errores, seguir creando la fiesta como una forma reconciliada de conciencia colectiva.

\section{Conclusiones}

La escritura de Evelio José desea un nuevo porvenir desde una hospitalidad que invita a cuestionar el fondo de nuestra cultura. ¿Qué pasa cuando se borra la memoria? El pueblo obliga a sanar nuestros desastres, a reinventar desde la creación una historia más incluyente. Gracias a la novela habla la sabiduría popular y colectiva, su ironía y su fiesta son manifestación de conciencia y posibilidad de convivencia que dignifica en toda su dimensión lo que es la vida y el hombre. La literatura como diría Deleuze es la encargada de llamar al pueblo que falta, es otra forma de decir, de significar y por lo tanto de recuperar un verdadero sentido existencial, de tejer una ética y estética vitalista. Escritura trazo, grito, grafía, aventura más allá de la representación oficial; escritura duda, provocación, transgresión, pensamiento y lectura de la historia, diferente.

Es preciso seguir reconstruyendo los relatos sin ninguna exclusión porque los fantasmas hablan. El otro, lo oculto, el secreto, el fantasma... enmascaran una realidad que tiene repercusiones en el presente, ellos, "los olvidados", poseen un valor ontológico, siempre están allí aunque ya no sean. La realidad ficcional demuestra una vez más su poder crítico frente al mundo real; es preciso deconstruir el dolor, indagar en las víctimas, en los derechos vulnerados.

En la actualidad diversos autores están abriendo nuevas lecturas de la salud desde la memoria: El cuerpo nunca miente de Alice Miller (2011), el inconsciente reprimido aparece en la historia de cada cuerpo como un espacio de resonancia que almacena dolores; Las fuentes de la vergüenza (2008) de Vincent de Gaulejac, reflexiona sobre la importancia de la sujetividad (sujeto), cada ser tiene su historia que contar. También existen aportes de obras clásicas como Lo inconsciente (1970) de Car Jung, que concibe los arquetipos como disposiciones psíquicas que sirven para interpretar situaciones humanas básicas como la muerte y la violencia que se construyen y deconstruyen a través de sueños y visiones. 
Todo lo anterior también justifica la necesidad de reconstruir una nueva visión de la memoria del dolor y de los llamados héroes, esto tiene implicaciones en la salud de todos. Afirma el investigador y divulgador catalán Eduardo Punset en su libro Viaje a la felicidad (2012), infortunadamente existe un ejercicio abyecto de poder, una de las armas para perpetuarlo ha sido el miedo que hace a la población más vulnerable, la obliga a callar para salvar su vida, realiza discriminaciones de colectivos históricamente discriminados; sostiene que esto trae consecuencias para la salud y la felicidad que es uno de sus sinónimos; la responsabilidad de los héroes y de los políticos es enorme: "la sociedad haría bien en exigirles una pureza de espíritu y de obra” (Punset, 2012, p. 182).

Por consiguiente, la escritura de Evelio toca un tema de impresionante actualidad y se une al pensar derridiano; propone una comunidad que no se reduce a la manipulación mediática de la presencia; concibe la creación como texto por venir, posibilidad del otro, de lo imprevisible, de la diferencia, de la desestabilización continua del orden y el poder. La búsqueda de nuevos relatos sigue siendo el signo de la creación y una puesta en escena de nuevas conciencias y libertad; ¿quién llega ahora?

\section{Referencias}

Abad, H. (2007). El olvido que seremos. Barcelona: Seix Barral.

Cixous, H., y Derrida, J. (2001). Velos. Prólogo y traducción de Mara Negrón. México: Siglo XXI.

. (2004). Lengua por venir. Langue à venir: seminario de Barcelona. Segarra, M. (Ed.). Barcelona: Icaria.

Derrida, J. (1989). La deconstrucción en las fronteras de la filosofía. En Peñalver, P. (Trad.). Introducción (1967). Barcelona: Ediciones Paidós.

. (1989). La escritura y la diferencia. En Peñalver, P. (Trad.). Barcelona: Editorial Anthropos.

. (1995). La voz y el fenómeno: introducción al problema del signo en la fenomenología de Husserl. Valencia: Pre-Textos. 
_. (2000). Dar la muerte. Peretti, C., y Vidarte, P. (Trad.). Barcelona: Ediciones Paidós Ibérica.

. (2008). De la gramatología. Del Barco, O., y Ceretti, C. (Trad.). México: Siglo XXI Editores.

De Gaulejac V. (s.f.). Las fuentes de la vergüenza. Buenos Aires: Mármol Izquierdo.

Fernández, R. (1976). Contra la leyenda Negra. La Habana. Recuperado de http:// core.ac.uk/download/pdf/16297989.pdf

Jefferson A. (2012). El cuerpo importa: el yo y el otro. En Bajtín y la Teoría de la cultura. Bogotá: Instituto Caro y Cuervo.

Jung, C. G. (1970). Lo inconsciente. Buenos Aires: Losada.

Marx C. (1974). Bolivar-leyenda y realidades. Medellín: Fondo Editorial La Oveja Negra, Ediciones Nueva Crítica. Colección Estudios Históricos-Colombia.

Miller, A. (2011). El cuerpo nunca miente. Buenos Aires: Tusquets Editores.

Muñoz, L. I. (1996). Filosofía del Realismo Pastuso. En Manual 18. Historia de Pasto (pp. 242-249). Pasto: Academia Nariñense de Historia, Alcaldía Municipal.

_. (2011). Mujeres del sur en la independencia de Nueva Granada. Pasto: Graficolor.

Nancy, J. L. (2009). La verdad de la democracia. Buenos Aires: Amorrortu.

Nietzsche, F. (1981). El origen de la tragedia. Sánchez, A. (Trad.). Madrid: Alianza.

Ospina, W. (2013). Pa'que se acabe la vaina. Bogotá: Planeta.

Patiño, C. (2011). La fiesta del tiempo destructor y regenerador, una lectura de Carnaval y Literatura: sobre la Teoría de la Novela y la cultura de la risa de MijailBajtin. En Revista Nexus. Universidad del Valle: Escuela de Comunicación Social.

Punset, E. (2012). Viaje a la felicidad. Las nuevas claves cientificas. Barcelona: Ediciones Destino.

Real Academia de la Lengua Española (RAE). (2012). Diccionario de la lengua española. España: RAE. Recuperado de http://www.rae.es/recursos/diccionarios/drae

Rosero, E. (2012). La carroza de Bolívar. Barcelona: Tusquets. 
. (2007). Los Ejércitos. Barcelona: Tusquets.

Sañudo, J. R. (1925, octubre). Estudios sobre la vida de Bolívar. Pasto: Editorial Díaz del Castillo y Cia.

Umberto, E. (1989). Los marcos de la libertad cómica. En Carnaval. México: F.C.E.

Verdugo, J. (2013). Carnaval y sociedad anómica colombiana en La carroza de Bolívar de Evelio José Rosero Diago. Ponencia que se deriva de la tesis doctoral Entre lo idílico y lo pavoroso, cinco novelas de autores de Nariño, Universidad de Antioquía, presentada en el simposio de "Pensamiento filosófico literario y estético latinoamericanos", Universidad de Nariño. Recuperado de ceilat.udenar.edu.co 